\title{
Editorial:
}

\section{El Mensaje de la Educación Inclusiva es Simple, pero su Puesta en Práctica es Compleja}

\author{
Cynthia Duk ${ }^{1 *}$ \\ F. Javier Murillo ${ }^{2}$ \\ ${ }^{1}$ Universidad Central de Chile, Chile \\ ${ }^{2}$ Universidad Autónoma de Madrid, España
}

Han pasado casi tres décadas de la renombrada Conferencia Mundial de Jomtien sobre Educación para Todos, organizada el año 1990 por la UNESCO, que marcó un hito en la agenda pública de los Estados y de las organizaciones de la sociedad civil, al consagrar el acceso universal a la educación y la satisfacción de las necesidades básicas de aprendizaje como un derecho que todos los niños, niñas y jóvenes tienen, sin excepción. Y también casi han pasado 25 años de la Conferencia Mundial de Salamanca que dio seguimiento a Jomtien en 1994, en el ámbito de las Necesidades Educativas Especiales, reconociendo el acceso y calidad como elementos fundamentales para garantizar igualdad de oportunidades.

La relevancia de la Declaración de Salamanca y su Marco de Acción es que acuñó por primera vez a nivel internacional el concepto de "educación inclusiva", reafirmando el compromiso de Educación para Todos de Jomtien, pero poniendo el foco en los grupos en mayor riesgo de exclusión, marginación y fracaso escolar, así como en la importancia de que todos los niños y niñas tengan la oportunidad de educarse "juntos" en las escuelas de su comunidad, relevando la idea de "escuela inclusiva".

Desde el planteamiento de Salamanca, la inclusión es concebida como un principio rector que debe orientar las políticas y prácticas educativas de todos los estudiantes y, por tanto, del sistema en su conjunto, dejando en claro que no se refiere ni restringe a los estudiantes con necesidades educativas especiales, aunque obviamente los incluye. Recordemos que dice exactamente:

\begin{abstract}
El principio rector de este Marco de Acción es que las escuelas deben acoger a todos los niños, independientemente de sus condiciones físicas, intelectuales, sociales, emocionales, lingüísticas $u$ otras. Deben acoger a niños discapacitados y niños bien dotados, a niños que viven en la calle y que trabajan, niños de poblaciones remotas o nómadas, niños de minorías lingüísticas, étnicas o culturales y niños de grupos o zonas desfavorecidas, o marginados. Todas estas condiciones plantean una serie de retos para los sistemas escolares... El mérito de las escuelas "integradoras" no es sólo que sean capaces de dar una educación de calidad a todos los niños; con su creación se da un paso muy importante para intentar cambiar las actitudes de discriminación, crear comunidades que acojan a todos y sociedades integradoras" (cabe subrayar que el término "integradoras" es usado como sinónimo de "inclusivas", en la versión en inglés de la declaración se utiliza el término "inclusive”).
\end{abstract}

Es bastante posible que si se hubiera escrito en la actualidad, el mismo planteamiento habría sido formulado de manera distinta. Pero estaremos de acuerdo que el mensaje de

*Contacto: cduk@ucentral.cl

ISSN: 0718-7378

www.rinace.net/rlei/ 
fondo sigue completamente vigente. No cabe duda de que los principios, propuestas y recomendaciones derivadas de Salamanca fueron visionarias y vanguardistas en su época. Uno de sus mayores méritos fue colocar en la mira a los niños/as más necesitados de educación, a los excluidos y discriminados, y tomar posición, desde el reconocimiento de sus derechos y dignidad como personas, en favor del enfoque de educación inclusiva como vía privilegiada para alcanzar el objetivo de Educación para Todos, "con todos", como quedó plasmado en algún documento sobre el tema.

En este sentido, es innegable el papel que jugó Salamanca en los orígenes de los conceptos de "educación inclusiva" y "escuela inclusiva", como también en su proyección alrededor del mundo, trascendiendo el campo de la educación especial, para convertirse progresivamente en un asunto que importa y adquiere cada vez más sentido para la educación general, como siempre debiera haber sido.

Sin pretender hacer un análisis detallado, es posible afirmar que el mensaje de la educación inclusiva ha tenido presencia con distintos matices, en la mayoría de los acuerdos e instrumentos internacionales generados con posterioridad a Salamanca, impactando a su vez las políticas y marcos normativos nacionales de numerosos países, que han adoptado medidas potentes para favorecerla y reducir los mecanismos de los sistemas que generan exclusión, segregación o bajo desempeño.

Un ejemplo palpable de ello es el ODS 4, único objetivo dedicado a la educación de la Agenda 2030 para el Desarrollo Sostenible de Naciones Unidas, al cual nos referimos extensamente en la editorial del número anterior (Murillo y Duk, 2017). Como se puede apreciar, su formulación hace hincapié en la inclusión y la equidad como fundamentos para una educación y un aprendizaje de calidad, comprometiendo a los países a trabajar en pro de este objetivo: "Garantizar una educación inclusiva, equitativa y de calidad y promover oportunidades de aprendizaje durante toda la vida para todos". Este planteamiento era algo inimaginable en la década de los 90, y denota el arraigo que el concepto de educación inclusiva ha alcanzado en el discurso internacional. Sin ir más lejos, a tal punto la inclusión ha penetrado en el lenguaje educativo que vemos como se multiplica su uso como adjetivo en diversos ámbitos, de modo de distinguir lo inclusivo/a. En la actualidad no sorprende a nadie, escuchar hablar de sistema y escuela inclusiva, de políticas, gestión o prácticas inclusivas, currículo inclusivo, incluso de profesor inclusivo. La instalación del enfoque inclusivo en el lenguaje educativo tiene sin duda un lado muy positivo, pero también nos advierte del riesgo que su uso indiscriminado se convierta en una etiqueta más, carente contenido y termine perdiendo significancia o siendo percibido como otra moda educativa.

En todo caso, pareciera que lo que fundamenta la referencia a lo inclusivo es la demanda de acceso igualitario a las oportunidades educativas y a una educación de calidad para todos los y las estudiantes, sustentada en el reconocimiento de las diferencias; es decir, una educación más equitativa. Desde esta perspectiva, inclusión, calidad y equidad serían tres conceptos estrechamente vinculados e interdependientes, tal como se refleja en el ODS 4 al incorporar en su definición esta triada. Sin embargo, si revisamos las metas que operacionalizan este ambicioso objetivo, es posible advertir que no dan cuenta suficientemente de la amplitud y alcances de su definición.

Ello nos lleva a reafirmar la idea de que el mensaje de la inclusión es simple, pero su puesta en práctica es muy compleja. Ello es debido, por una parte, a las diversas comprensiones que giran en torno a esta noción y, por otra, a la multiplicidad de factores 
que interactúan en cada realidad para su implementación y desarrollo continuo. Pero si cabe más compleja es aún su puesta en marcha en contextos donde priman modelos educativos que se contraponen a los principios que orientan la educación inclusiva y que ejercen presión en la dirección contraria o no deseada, lo que no resulta fácil contrarrestar.

Sin ánimo de desmoralizarnos, para finalizar queremos compartir un aporte digno de mencionar, la "Guía para Asegurar la Inclusión y la Equidad en la Educación”, publicada por la UNESCO el 2017, para apoyar a los países y a los tomadores de decisiones en los procesos de diseño, implementación y monitoreo de políticas que favorezcan la inclusión y equidad, en el marco del oDs 4.

En ella se señala que, la incorporación de los principios de equidad e inclusión en la política educativa implica lo siguiente (UNESCO, 2017, p. 13):

- Valorar la presencia, la participación y los logros de todos los estudiantes, independientemente de sus contextos y características personales.

- Reconocer los beneficios de la diversidad de los y las estudiantes y cómo vivir con las diferencias y aprender de ellas.

- Recopilar, cotejar y evaluar evidencias sobre las barreras al acceso de los niños y de las niñas a la educación, a la participación y a los logros, prestando especial atención a los y las estudiantes que pueden estar más expuestos al fracaso, la marginación o la exclusión.

- Alcanzar un entendimiento común de que los sistemas educativos más incluyentes y equitativos tienen el potencial de promover la igualdad de género, reducir las desigualdades, desarrollar las capacidades de los docentes y del sistema y fomentar entornos de aprendizaje de apoyo. Estos diversos esfuerzos, a su vez, contribuirán a una mejora general en la calidad de la educación.

- Movilizar a los actores claves del sistema educativo y de la comunidad para propiciar las condiciones para un aprendizaje inclusivo y una comprensión más amplia de los principios de inclusión y equidad.

- Aplicar cambios de forma eficaz y supervisar su impacto, reconociendo que el logro de la inclusión y de la equidad en la educación es un proceso continuo, más que un esfuerzo único.

La pregunta de cajón, que se repite una y otra vez, y sigue abierta es: ¿cómo acortamos la distancia entre el discurso de la inclusión cargado de buenas intenciones y la práctica real de la educación inclusiva?

\section{Referencias}

Murillo, F. J. y Duk, C. (2017). El ODS 4 (y el 16) como meta para los próximos años. Revista Latinoamericana de Educación Inclusiva, 11(2), 11-13. https://doi.org/10.4067/So71873782017000200001

UNESCO. (2017). Guía para asegurar la inclusión y la equidad en la educación. París: UnEsco. http://unesdoc.unesco.org/images/0025/002595/259592s.pdf 